\title{
Conditioned rewarding effects of morphine and methadone in mice pre-exposed to cocaine
}

\author{
Małgorzata Hołuj ${ }^{1}$, Adam Bisaga ${ }^{2}$, Piotr Popik ${ }^{1,3}$ \\ ${ }^{1}$ Behavioral Neuroscience and Drug Development, Institute of Pharmacology, Polish Academy of Sciences, \\ Smętna 12, PL 31-343 Kraków, Poland \\ ${ }^{2}$ Department of Psychiatry, Columbia University College of Physicians and Surgeons and the New York State \\ Psychiatric Institute, New York, USA \\ ${ }^{3}$ Faculty of Health Sciences, Jagiellonian University Collegium Medicum, Michałowskiego 12, PL 31-126 Kraków, \\ Poland
}

Correspondence: Piotr Popik, e-mail: nfpopik@cyf-kr.edu.pl

\begin{abstract}
:
Background: Methadone is widely accepted as the most effective treatment of opioid dependence. However, clinical observations indicate that the medication is less effective in individuals abusing cocaine. Diminished therapeutic efficacy of methadone in cocaine users is intriguing, but its mechanism has not been studied.

Methods: Here, the conditioned place preference (CPP) procedure was used to examine the effects of the dose, number of conditioning sessions and pre-exposure to cocaine on the rewarding effects of morphine and methadone. Vehicle-pre-exposed and cocainesensitized mice (five injections of $10 \mathrm{mg} / \mathrm{kg}$ over 16 days) were conditioned using methadone $(0,0.1,0.5,3$, and $5 \mathrm{mg} / \mathrm{kg})$ or morphine $(0,1$, and $10 \mathrm{mg} / \mathrm{kg})$. Place preference was measured after one and again after two additional conditioning sessions.

Results: As expected, morphine at $10 \mathrm{mg} / \mathrm{kg}$ produced CPP following just one conditioning session. While a single conditioning session with $1 \mathrm{mg} / \mathrm{kg}$ of morphine produced no CPP, the rewarding effect became apparent following two additional conditioning sessions as well as in mice pre-exposed to cocaine. Methadone produced CPP following one conditioning session at doses of $0.5,3$ and $5 \mathrm{mg} / \mathrm{kg}$. However, unlike with morphine, methadone's rewarding effect was not enhanced by two additional conditioning sessions or by pre-exposure with cocaine.
\end{abstract}

Conclusions: Prior exposure to cocaine increases unconditioned motivational effects of morphine but not of methadone.

Key words:

conditioned reward, opioids, morphine, methadone, cocaine, sensitization

\section{Introduction}

Opioid agonist methadone is considered to be the most effective treatment for opioid dependent individuals when used as a part of a comprehensive treatment program $[15,22]$. Methadone diminishes craving for heroin and dramatically reduces levels of her- oin use and related mortality. When dosed properly, methadone does not produce intoxication or euphoria and displays low abuse potential as compared to other opioids such as morphine or heroin, permitting patients to remain on stable doses over long time-periods.

The effectiveness of methadone is limited, however, in individuals who are using cocaine, where it 
results in higher rates of heroin use and treatment dropout $[12,19,21,37]$. Considering that concurrent use of cocaine is widespread in methadone treatment programs, seen in almost $50 \%$ of patients $[5,12,17$, 25], the impact of cocaine on the effectiveness of methadone is of central importance. Similarly, a negative effect of concurrent use of cocaine has also been noted in individuals treated with buprenorphine [21, 37]. The reason for the decreased therapeutic benefit of methadone in cocaine users remains unknown. One of the proposed mechanisms could involve the pharmacokinetic interaction whereby concurrent cocaine use may decrease the blood level of methadone rendering it less effective [23]. Cocaine may also alter the reinforcing effect of methadone or heroin. For instance, in patients previously exposed to cocaine, methadone may produce euphoric effects, which can be destabilizing for patients. Alternatively, cocaine may increase the euphorigenic and unconditioned motivational effects of heroin leading to the increase of heroin craving and subsequent escalation of use. When an opiate and cocaine are taken together, usually as an injectable or smoked combination ("speedball"), the euphoric effect and the craving for heroin is enhanced [9], and this combination has particularly deleterious effect on health and functioning of users [17]. Further understanding of the impact of cocaine on the rewarding effects of methadone and morphine may help in developing treatment strategies to maximize the clinical effectiveness of methadone.

The conditioned place preference (CPP) test assesses the approach to conditioned rewarding stimuli. In rats, both morphine [3] and methadone [32] reliably produce a conditioned place preference; for review (see Tzschentke [35]). The conditioned rewarding effects of drugs including morphine depend on the number of conditioning sessions and are related to the drug dose, with low doses and low number of conditioning sessions producing relatively weak CPP response [24]. Investigation of CPP in such conditions allows assessing purported facilitation of the response, as was shown for cocaine pre-treatment on the rewarding effects of morphine [30]. Investigation of CPP with additional conditionings and/or relatively high doses of drugs allows assessing whether the preexposure to cocaine could further increase purportedly maximal place preference response.

The present experiment was designed to study whether pre-exposure to cocaine at doses producing long-term behavioral effects, as evidenced by loco- motor sensitization, would alter the rewarding effects of methadone and morphine measured using CPP. We hypothesized that pre-exposure to cocaine will increase the rewarding effects of both methadone and morphine.

\section{Materials and Methods}

\section{Subjects}

Male C57BL/6 (Charles River, Germany) mice weighing 23-26 g were used for all experiments. The animals were housed in groups of 10 in standard plastic cages at $21 \pm 1{ }^{\circ} \mathrm{C}$, and $\sim 50 \%$ humidity, with a $12 \mathrm{~h}$ light/dark cycle (lights on: 7:00, off: 19:00). Food and water were available ad libitum. Each experimental group consisted of 8-10 mice per treatment. All animals were used only once. The experiments were conducted in accordance with the NIH Guide for the Care and Use of Laboratory Animals and were approved by the Ethics Committee for Animal Experiments, Institute of Pharmacology, PAS.

\section{Drugs}

Morphine $\mathrm{HCl}$ (Polfa, Kraków, Poland), cocaine $\mathrm{HCl}$ (provided by the National Institute on Drug Abuse, Research Triangle Institute, Research Triangle Park, NC USA) and (R,S)-methadone $\mathrm{HCl}$ (Sigma Aldrich, USA kindly provided by Dr E. Taracha, Institute of Psychiatry and Neurology, Warszawa, Poland) were dissolved in sterile physiological saline and given in the volume of $10 \mathrm{ml} / \mathrm{kg}$ of body weight, intraperitoneally (ip). The doses of morphine are expressed as free base.

\section{General procedure}

The experiments consisted of 3 successive phases: 1) exposure to repeated doses of cocaine to induce behavioral sensitization over a 16 day period, 2) one week of rest in the home cages, and 3) conditioned place preference procedure over an 11 day period.

\section{Cocaine-induced sensitization}

Sixteen-beam activity meters (Opto M3 Activity Meter, Columbus Instruments, OH, USA) were used to 
assess locomotor activity. Mice were monitored in acrylic cages $(23.5 \times 13.5 \times 13 \mathrm{~cm})$ placed in the activity monitor frame. Each monitor contained two sensor panels that detected horizontal movements (i.e., walking), but not rearing or grooming. Infrared light beams from the sensor panels were spaced $2.54 \mathrm{~cm}$ apart and photo beam interruptions were assessed by Columbus Instruments software. After $1 \mathrm{~h}$ of habituation to the experimental room equipped with a dim indirect light and a radio receiver delivering ambient white-noise $(70 \mathrm{~dB})$, the animals were acclimated to monitoring cages for $30 \mathrm{~min}$. Subsequently, the animals received either ip injections of the vehicle or $10 \mathrm{mg} / \mathrm{kg}$ of cocaine, after which their locomotor activity (number of crossings of the infrared light beams) was monitored for the following $90 \mathrm{~min}$ at $10 \mathrm{~min}$ intervals. This procedure was repeated 5 times every 3-5 days. Place conditioning sessions with opioids were carried out 7 days after cocaine sensitization.

\section{Conditioned place preference procedure}

The CPP apparatus consisted of 3 rectangular arms $(30 \times 15 \times 20 \mathrm{~cm})$ spaced at $120^{\circ}$ from each other, all accessible from a triangular (central) platform [28]. The apparatus was made of opaque plastic material (Metaplex) and the three arms differed in distinctive visual, tactile and olfactory cues. The white arm "A" had a black floor with small holes in it and was marked with a drop of Peppermint Odor (NDC0395-1913-91 Humco, TX, USA), the black arm "B" with a white, rough floor was marked with the drop of Anise Odor (NDC-0395-2015-91, Humco, TX, USA), and the other black arm "C" with a plain black floor had no odor. These distinct tactile, olfactory and visual cues served as conditioned stimuli [2]. The guillotine-doors made of the material corresponding to the respective wall colors, were inserted during conditioning sessions and removed during the tests. During testing, the location of the mouse was monitored through a closed circuit TV camera positioned directly above the apparatus. The testing room had a dim, indirect lighting, comprising of two $15 \mathrm{~W}$ bulbs positioned about $1 \mathrm{~m}$ above the apparatus (illumination at the floors $=\sim 14-16$ lux). A loudspeaker (radio receiver) positioned $\sim 1 \mathrm{~m}$ above the apparatus delivered ambient white noise $(70 \mathrm{~dB})$. The floors were washed and dried regularly so as to prevent accumulation of excrement.
The experiment was carried out over the 11 study days using the following schedule: adaptation (day 1), pre-conditioning test (day 2), conditioning session with morphine or methadone (day 3), conditioning session with vehicle (day 4), and the post-conditioning test \#1 (day 5). After one day of break, the animals were additionally conditioned with opioids (days 7 and 9) and vehicle (days 8 and 10), and the post-conditioning test \#2 was carried out on day 11.

During the adaptation, mice were carried into the testing room, weighed, and handled by experimenter. This phase was intended to reduce the novelty and stress associated with handling and injections. During the preconditioning test, mice were placed individually on the central triangular platform of the apparatus with free access to all three arms for $20 \mathrm{~min}$. The time spent in each arm was recorded. The arms " $\mathrm{A}$ ", " $\mathrm{B}$ " and " $\mathrm{C}$ " were preferred by $26.25,33.75$ and $40 \%$ of mice, respectively. To avoid any preference bias before conditioning sessions, for each mouse, the two arms registering the most similar preferences were identified, one of which was randomly chosen to be paired with opioids and the other with vehicle (an unbiased CPP procedure). During conditioning sessions, mice received methadone, morphine, or vehicle immediately before being placed into the respective arm of the apparatus for $40 \mathrm{~min}$. The postconditioning tests were carried out similarly to the preconditioning test, with mice placed individually on the central triangular platform of the apparatus with free access to all arms for $20 \mathrm{~min}$.

\section{Data presentation and statistics}

Cocaine-induced sensitization was assessed using mixed-design three-way ANOVA (treatment $x$ day $\times$ time) on locomotor activity data recorded during the first $30 \mathrm{~min}$ of experimentation, which corresponds to the most significant stimulatory effects of the drug. The Newman-Keuls test was used for the post-hoc analysis. In addition, Pearson's correlation and linear regression analyses were used to assess the relationship between the magnitude of cocaine-induced hyper-activity (the Area Under the Curve; AUC, covering locomotor activity measured up to 30 min following drug treatment, on a given day) and the day of treatment.

Conditioned place preference data were assessed using $\triangle$ CPP times (time spent in drug-paired compartment during the given: first or second postconditioning test minus time spent in the drug-paired compartment during the pre-conditioning test). These 
data were assessed with 2-way General Linear Models (GLM) ANOVA with one between subjects factor (treatment with methadone, morphine, or vehicle) and one within subjects factor (the number of conditioning sessions: $1 v s$. 3). A restricted set of planned comparisons, selected a priori (contrasts) were used to test study main hypotheses. The full factorial 3-way mixed design ANOVA could not model all investigated interactions because, due to ethical concerns, some controls were omitted. Among the omitted groups were cocaine-sensitized/vehicle-conditioned animals, because there was no reason to assume that prior cocaine sensitization could result in place preference due to vehicle conditioning sessions [30]. We also did not test the effects of morphine at $10 \mathrm{mg} / \mathrm{kg}$ in cocaine-sensitized mice because the effect of that dose of the drug was already maximal in vehiclepretreated animals.

Pearson's correlation and linear regression analyses were used to assess the relationship between the magnitude of cocaine-induced hyper-activity (the sum of 5 locomotor activity tests data, each expressed as AUC) and the effectiveness of conditioning sessions with opioids ( $\triangle \mathrm{CPP}$ at post-conditioning tests \#1 and \#2).

The data fulfilled criteria of normal distribution. The $\alpha$ value was set at $p<0.05$. Statistical analyses were performed with the use of Statistica 9.1 for Windows.

\section{Results}

\section{Cocaine-induced sensitization}

Figures $1 \mathrm{~A}$ and $1 \mathrm{~B}$ show the results of cocaine sensitization experiment. Repeated measures ANOVA revealed the significant effects of treatment $[\mathrm{F}(1,17)=$ $62.1, \mathrm{p}<0.001]$, day of sensitization $[\mathrm{F}(4,68)=5.48$, $\mathrm{p}<0.001]$, time of measurement $[\mathrm{F}(3,51)=39.97$, $\mathrm{p}<0.001]$ as well as all interactions $(\mathrm{p}<0.001)$ including treatment $\times$ day $\times$ time interaction $[\mathrm{F}(12,204)$ $=6.45, \mathrm{p}<0.001]$. The post-hoc analysis demonstrated an increase in locomotor activity over tests in the cocaine-treated group but not in the vehicletreated group. The development of sensitization was evidenced by an increased locomotor activity not only at the $10^{\text {th }}$ but also at the $20^{\text {th }}$ min after administration on days 11 and 16 of testing, as compared with day 1 locomotor activity data (Fig. 1A). In addition, Fig- ure 1B demonstrates a positive and significant correlation between the day of treatment and locomotor activity expressed as AUC in cocaine-treated mice $\left(\mathrm{r}^{2}=\right.$ $0.88 ; \mathrm{p}<0.05)$ but not in vehicle-treated mice $\left(\mathrm{r}^{2}=\right.$ $0.35 ; \mathrm{p}=0.28)$.

\section{Effects of the dose and the number of con- ditioning sessions on morphine-induced CPP in control and in cocaine sensitized mice}

ANOVA revealed the significant effects of treatment $[F(3,34)=9.54, p<0.001]$, but not of the number of conditioning sessions $[F(1,34)=2.86]$. Planned comparisons tests revealed that among vehiclepretreated mice, morphine at $10 \mathrm{mg} / \mathrm{kg}$ produced significant CPP after one conditioning session, and that this effect was not enhanced following additional conditioning sessions (Fig. 2A). In vehicle-pretreated animals, morphine at $1 \mathrm{mg} / \mathrm{kg}$ produced no CPP after one conditioning session, but a significant CPP emerged after two additional conditioning sessions. In contrast, in cocaine-sensitized mice, morphine at $1 \mathrm{mg} / \mathrm{kg}$ produced significant CPP already after one conditioning session, and this effect was not enhanced following additional conditioning sessions.

The magnitude of cocaine locomotor sensitization positively and significantly correlated with the effectiveness of morphine-induced CPP when measured after three conditioning sessions $\left(r^{2}=0.5 ; p<0.05\right)$ but not after one conditioning session $\left(r^{2}=0.14\right.$; Fig $\left.2 B\right)$.

\section{Effects of the dose and the number of conditioning sessions on methadone-induced CPP in control and in cocaine sensitized mice}

Methadone produced dose-related conditioned rewarding effects in cocaine-naive mice (Fig. 3A). Two-way ANOVA with the dose as between factor and the number of conditionings as a repeated factor revealed significant effects of treatment $[\mathrm{F}(4,43)=$ $6.41, \mathrm{p}<0.001]$ but not of the number of conditioning sessions $[F(1,43)=0.32]$. Planned comparisons tests revealed that following one conditioning session, methadone produced significant CPP at doses of 0.5 , 3 and $5 \mathrm{mg} / \mathrm{kg}$ (but not at $0.1 \mathrm{mg} / \mathrm{kg}$ ), and that this effect was less pronounced following two additional conditioning sessions since only the dose of $3 \mathrm{mg} / \mathrm{kg}$ produced significant CPP. In contrast to that of morphine (Fig. 2A), the CPP produced by methadone did not increase following additional conditioning sessions. 
A
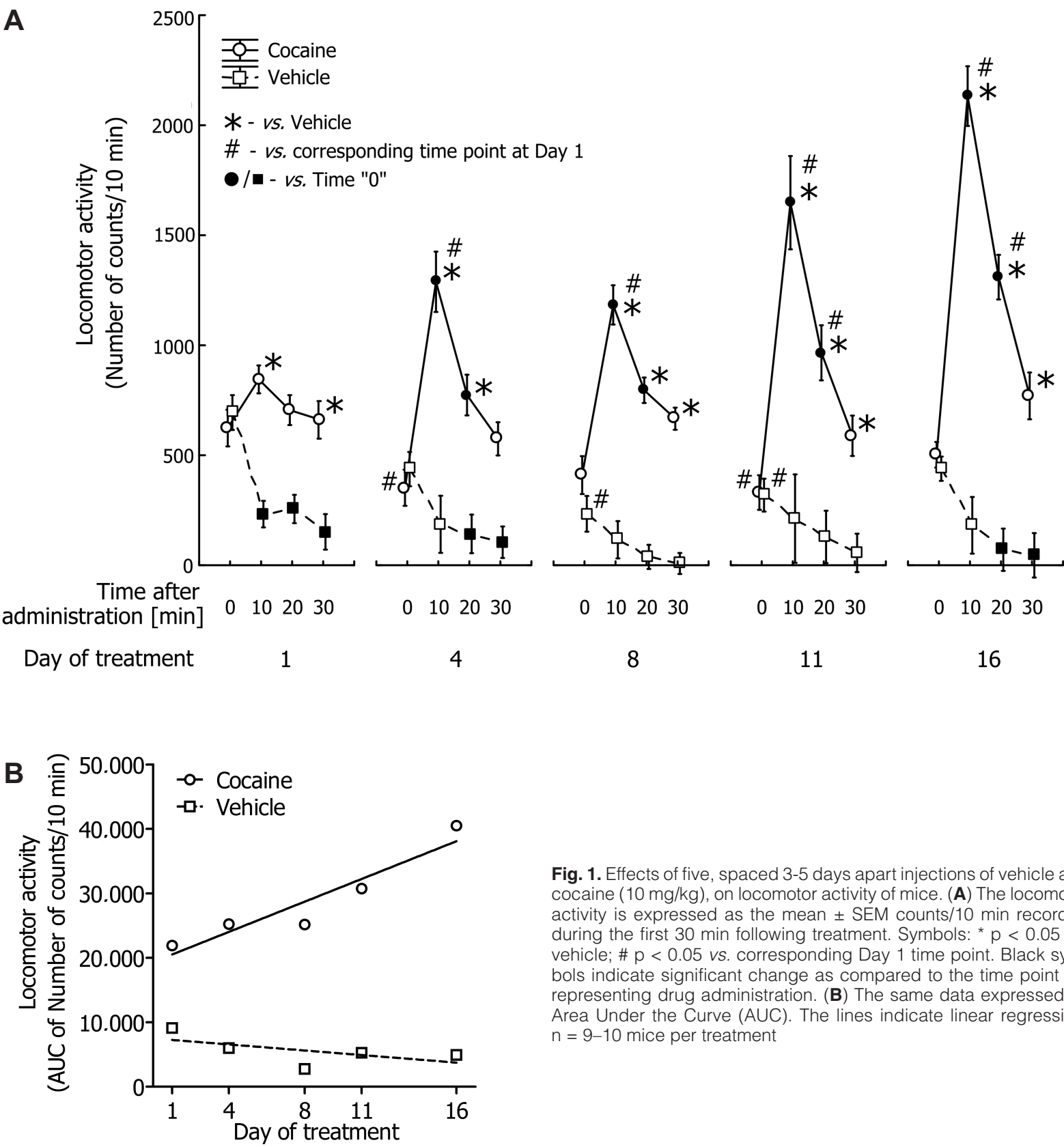

Fig. 1. Effects of five, spaced 3-5 days apart injections of vehicle and cocaine $(10 \mathrm{mg} / \mathrm{kg}$ ), on locomotor activity of mice. (A) The locomotor activity is expressed as the mean \pm SEM counts/10 min recorded during the first $30 \mathrm{~min}$ following treatment. Symbols: * $p<0.05$ vs. vehicle; \# $\mathrm{p}<0.05$ vs. corresponding Day 1 time point. Black symbols indicate significant change as compared to the time point " 0 " representing drug administration. (B) The same data expressed as Area Under the Curve (AUC). The lines indicate linear regression. $n=9-10$ mice per treatment

Methadone doses that produce either no CPP $(0.1 \mathrm{mg} / \mathrm{kg})$ or minimal CPP $(0.5 \mathrm{mg} / \mathrm{kg})$ were chosen for the experiment assessing the impact of cocaine pre-exposure on methadone-induced CPP (Fig. 3B). ANOVA revealed significant effects of treatment $[\mathrm{F}(4,41)=6.20, \mathrm{p}<0.001]$ but not of the number of conditioning sessions $[\mathrm{F}(1,41)=0.28]$. Planned comparisons tests revealed that in vehicle-preexposed mice, methadone produces significant CPP $(0.5 \mathrm{mg} / \mathrm{kg})$ following one conditioning session, and that this effect is not increased following additional conditioning sessions, confirming the results of the experiment carried out in mice not subjected to the sensitization procedure (Fig. 3A). At $0.1 \mathrm{mg} / \mathrm{kg}$, methadone produced no CPP independently of the number of conditioning sessions. Cocaine sensitization affected CPP neither in $0.1 \mathrm{mg} / \mathrm{kg}$ nor in 0.5 $\mathrm{mg} / \mathrm{kg}$ methadone-conditioned mice.

The effectiveness of cocaine sensitization did not correlate with the intensity of $0.1 \mathrm{mg} / \mathrm{kg}$ methadoneinduced CPP following neither one $\left(\mathrm{r}^{2}=0.21\right)$ nor three conditioning sessions $\left(r^{2}=0.001\right)$. Similarly, the 
Fig. 2. (A) Effects of the dose, number of conditioning sessions and prior cocaine sensitization on morphine-induced CPP in mice. Vehicle-pre-exposed animals were conditioned to the effects of vehicle, 10 or $1 \mathrm{mg} / \mathrm{kg}$ of morphine once (bars on the left) and then twice more (bars on the right). An additional group of cocainesensitized mice was similarly conditioned to the effects of $1 \mathrm{mg} / \mathrm{kg}$ of morphine. After one conditioning session, significant CPP was observed in vehicle-pre-exposed, $10 \mathrm{mg} / \mathrm{kg} \mathrm{mor}$ phine-conditioned animals (the "positive control") and in cocaine-sensitized, $1 \mathrm{mg} / \mathrm{kg}$ morphine-conditioned animals: ${ }^{*} p<0.05$ vs. respective vehicle. Morphine at $1 \mathrm{mg} / \mathrm{kg}$ produced significantly higher preference in $\mathrm{co}-$ caine- than in vehicle-pre-exposed mice: $\Phi: p<0.05$ vs. vehicle-pre-exposed, $1 \mathrm{mg} / \mathrm{kg}$ morphine-conditioned animals. In vehicle-pre-exposed mice, the dose of morphine that was ineffective following one conditioning session produced significant CPP following $\# \mathrm{p}<0.05 . \mathrm{n}=9-10$ mice per treatment. (B) The effectiveness of cocaine sensitization positively and signifimorphine-induced CPP measured following three conditioning sessions, but not after only one such session two additional conditioning sessions: cantly correlates with the intensity of

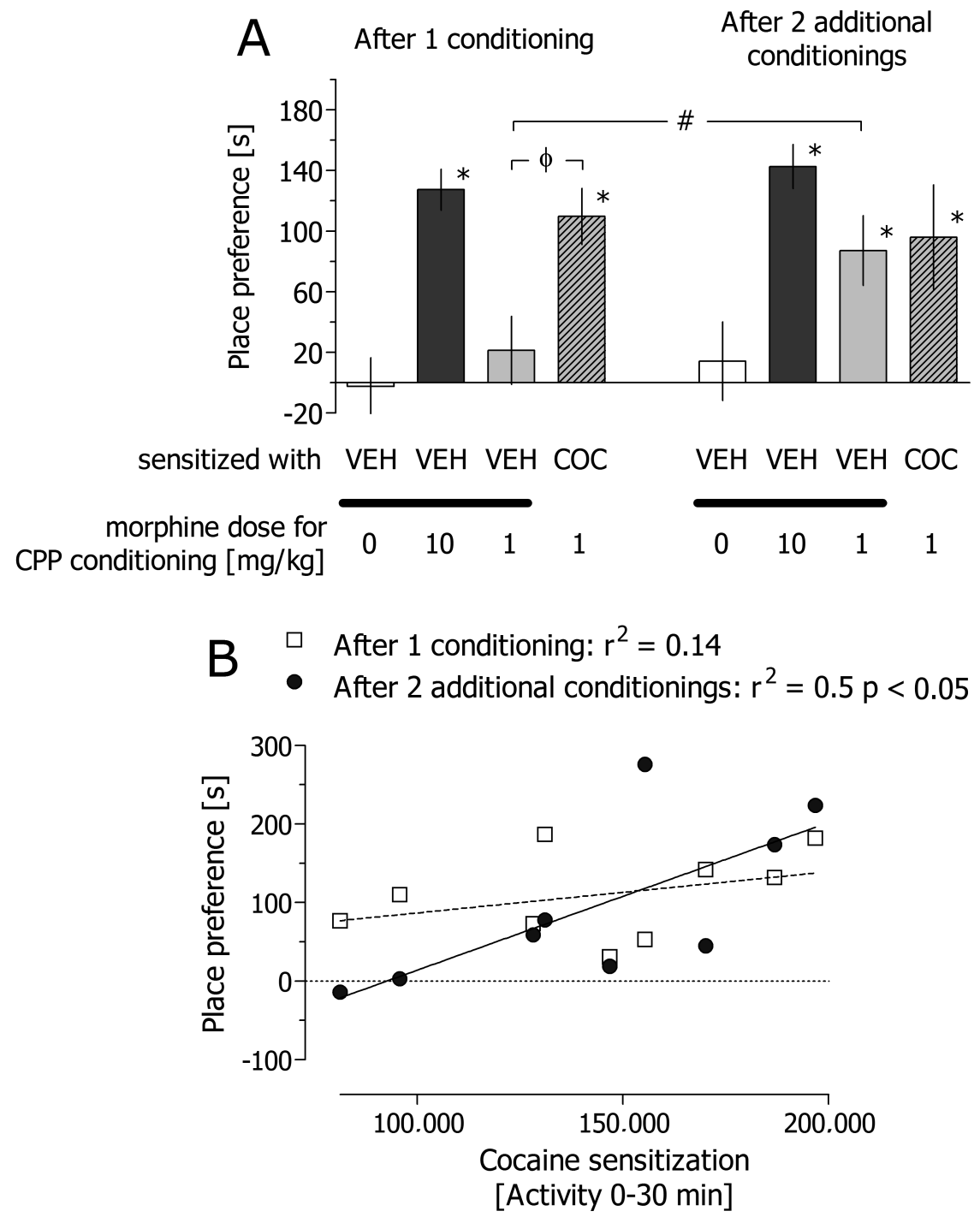

effectiveness of cocaine sensitization did not correlate with the intensity of $0.5 \mathrm{mg} / \mathrm{kg}$ methadone-induced CPP following neither one $\left(\mathrm{r}^{2}=0.02\right)$ nor three conditioning sessions $\left(\mathrm{r}^{2}=0.15\right)$.

\section{Discussion}

Both morphine and methadone at relatively high doses produced robust place preference in naive mice, even after one conditioning session. Exposure to cocaine prior to place conditioning sessions rendered mice more sensitive to the rewarding effects of a low dose of morphine. In contrast, pre-exposure to cocaine did not alter the rewarding effects of methadone.

Our results are consistent with prior studies showing that opioid receptor agonists are capable of producing CPP [3, 24, 32]. Only one previous study, using rats, demonstrated CPP induced by methadone $(1-10 \mathrm{mg} / \mathrm{kg}$; the rewarding effects peaking at $4 \mathrm{mg} / \mathrm{kg}$ ) after three conditioning sessions [32]. In the present study with mice, we have shown that similarly to one with morphine, a single conditioning session with methadone, at doses $0.5-5 \mathrm{mg} / \mathrm{kg}$, is sufficient to produce CPP, confirming that methadone has acute rewarding effects similar to that of morphine. Present data confirm also earlier observations showing that animals exposed to repeated, behaviorally-sensitizing doses of cocaine, develop morphine place preference 


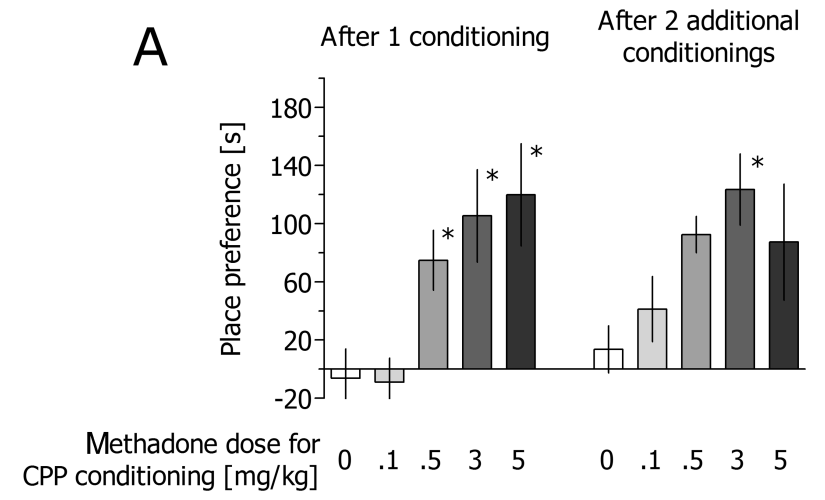

B

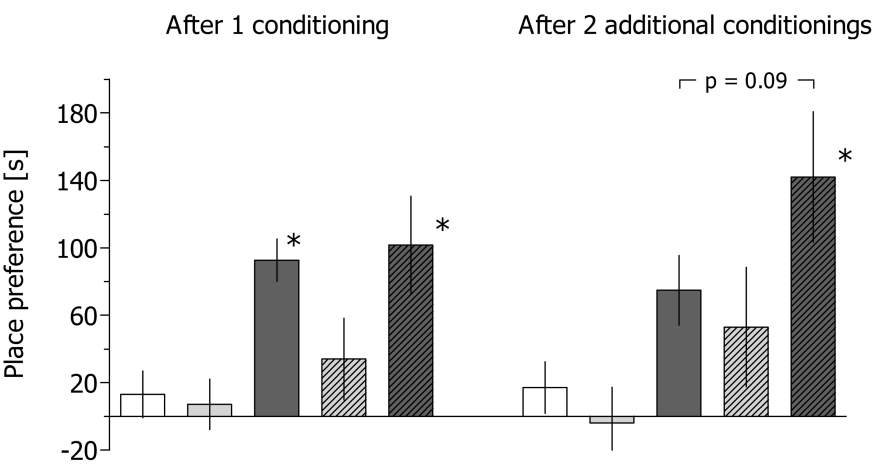

Sensitized with VEH VEH VEH COC COC

Methadone dose for CPP conditioning $[\mathrm{mg} / \mathrm{kg}]$ $\begin{array}{lllll}0 & 0.1 & 0.5 & 0.1 & 0.5\end{array}$
Fig. 3. (A) Dose-related rewarding effects of methadone following one and two additional conditioning sessions in mice not subjected to the sensitization procedure. Symbols: * $p<0.05$ vs. respective vehicle. $\mathrm{n}=9-10$ mice per treatment. (B) Effects of the dose, number of conditioning sessions and prior cocaine sensitization on methadone- induced CPP in mice. The medication did not produce stronger preference in cocaine-sensitized animals than in vehicle-pre-exposed animals, even following three conditioning sessions with a dose of $0.5 \mathrm{mg} / \mathrm{kg}$ ( $\mathrm{p}=$ 0.09). Furthermore, additional conditioning sessions appeared not to potentiate CPP. Symbols: * $p<0.05$ vs. VEH-O controls (pre-exposed to vehicle and conditioned with vehicle). $\mathrm{n}=$ 8-10 mice per treatment more easily than animals that were not exposed to cocaine [30].

The most interesting and somewhat unexpected finding of the present study is the differential effect of cocaine sensitization on the rewarding effects of morphine and methadone. To our knowledge, such direct comparison of the rewarding effects of both opioids has never been investigated before in the same experimental setting. This difference may be related to the variable pharmacodynamic and/or pharmacokinetic effects of these opioids. Sensitization is regarded as an adaptive process of mesolimbic dopamine transmission that may augment the incentive salience of drugs of abuse [29], and thus enhance their ability to serve as positive reinforcers. Exposure to cocaine can lead to sensitization of both locomotor activity and dopamine release in the ventral striatum [13, 36]. These neuroadaptive alterations of dopaminergic transmission are likely to facilitate the unconditioned motivational effects of morphine and methadone and/or the expression of opioid-induced place preference, because opioid-induced CPP is based on dopa- mine mesolimbic system [20, 31]. Nonetheless, the data showing similar effective doses of morphine and methadone to stimulate dopamine release [7] do not help in explaining differential effect of cocaine sensitization on the rewarding effects of both opioids. Similarly, cocaine-induced facilitation of learning [14] is unlikely to explain present results because one would have to assume that the intermittent cocaine administration that ended 1 week before the beginning of CPP test could enhance place conditioning. In this regard, Krueger et al. [16] have demonstrated that subchronic treatment with cocaine, followed by a drug-free period of 2 weeks resulted in impairments in reversal learning and working memory suggesting induction of long-lasting attenuation of cognitive functions.

Pharmacokinetic differences between methadone and morphine could contribute to their dissimilar sensitivity to cocaine exposure. Methadone has a much longer biological half-life time $(5-130 \mathrm{~h}$ in humans and 70-90 $\mathrm{min}$ in rats $[8,26])$ than morphine $(1-7 \mathrm{~h}$ in humans and $28 \mathrm{~min}$ in mice $[1,11])$. Prolonged ac- 
tion of methadone at opiate receptors could render its effects less sensitive to prior cocaine sensitization as compared with morphine. For instance, Leri et al. [18] proposed that the tonic elevation in basal levels of dopamine induced by methadone impair the ability of this system to develop changes in response to phasic influences of related doses and effects of other reinforcers.

Finally, while both drugs display $\mu$ opiate receptor agonistic properties, the d-isomer of methadone also inhibits the NMDA glutamate receptor [10], and attenuates morphine-induced tolerance in animal models [6]. NMDA receptor antagonists are known to inhibit the development of morphine-induced CPP [27] and therefore in the present setting, the NMDA receptor antagonistic properties of methadone might have prevented cocaine-induced facilitation of conditioned reward. For instance, since additional conditionings result in a stronger association between the effects of the drug and the environment, the development of such associations could be reduced in methadonetreated animals whose cognitive abilities were purportedly compromised. This is supported by recent studies demonstrating that morphine produces more pronounced neuroadaptive changes than methadone at electrophysiological, molecular and behavioral levels $[4,33,34]$.

Our initial hypothesis was that cocaine preexposure enhances the rewarding effect of both methadone and morphine and that those effects limit the therapeutic effectiveness of methadone. It has been known that the therapeutic effects of methadone in cocaine-free subjects are not directly related to the rewarding properties of this medication. However, it was not known whether cocaine pre-exposure would render methadone more rewarding, and thus, destabilizing for patients. Present findings confirm that cocaine pre-exposure impacts subsequent effects of morphine but also demonstrate that cocaine preexposure does not affect rewarding effects of methadone. Therefore, we postulate that the decrease in therapeutic efficacy of methadone in cocaine users is due to an increase in craving and enhanced rewarding effects of heroin, and not due to increased euphoric effects of the medication.

Our observations have implications for treatment of opioid dependence. Patients with a history of cocaine use who are treated with methadone may find heroin particularly rewarding, which may lead to an escalation of heroin use and subsequent worsening of clinical condition. Such patients may therefore require higher doses of methadone to minimize craving and the use of heroin as well as require behavioral interventions specifically targeting heroin cravings and closer monitoring of drug use to prevent destabilization and treatment dropout. Future clinical studies may test the effectiveness of these interventions as a treatment strategy for cocaine-using individuals who do not respond to a standard treatment.

\section{Acknowledgments:}

Funding for this study was provided by the Statutory Activity of Institute of Pharmacology, Polish Academy of Sciences (M.H., P.P.) and the New York State Psychiatric Institute (A.B.). All authors declare that they have no conflict of interest.

\section{References:}

1. Aderjan RE, Skopp G: Formation and clearance of active and inactive metabolites of opiates in humans. Ther Drug Monit, 1998, 20, 561-569.

2. Barr GA, Paredes W, Bridger WH: Place conditioning with morphine and phencyclidine: dose dependent effects. Life Sci, 1985, 36, 363-368.

3. Beach HD: Morphine addiction in rats. Canad J Psychol, 1957, 11, 104-112.

4. Bobula B, Hess G: Effects of morphine and methadone treatments on glutamatergic transmission in rat frontal cortex. Pharmacol Rep, 2009, 61, 1192-1197.

5. Condelli WS, Fairbank JA, Dennis ML, Rachal JV: Cocaine use by clients in methadone programs: significance, scope, and behavioral interventions. J Subst Abuse Treat, 1991, 8, 203-212.

6. Davis AM, Inturrisi CE: d-Methadone blocks morphine tolerance and N-Methyl-d-Aspartate- induced hyperalgesia. J Pharmacol Exp Ther, 1999, 289, 1048-1053.

7. Di Chiara G, Imperato A: Opposite effects of mu and kappa opiate agonists on dopamine release in the nucleus accumbens and in the dorsal caudate of freely moving rats. J Pharmacol Exp Ther, 1988, 244, 1067-1080.

8. Eap CB, Buclin T, Baumann P: Interindividual variability of the clinical pharmacokinetics of methadone: implications for the treatment of opioid dependence. Clin Pharmacokinet, 2002, 41, 1153-1193.

9. Foltin RW, Fischman MW: The cardiovascular and subjective effects of intravenous cocaine and morphine combinations in humans. J Pharmacol Exp Ther, 1992, 261, 623-632.

10. Gorman AL, Elliott KJ, Inturrisi CE: The d- and 1- isomers of methadone bind to the non- competitive site on the $N$-methyl-d-aspartate (NMDA) receptor in rat forebrain and spinal cord. Neurosci Lett, 1997, 223, 5-8.

11. Handal M, Grung M, Skurtveit S, Ripel A, Morland J: Pharmacokinetic differences of morphine and 
morphine-glucuronides are reflected in locomotor activity. Pharmacol Biochem Behav, 2002, 73, 883-892.

12. Hartel DM, Schoenbaum EE, Selwyn PA, Kline J, Davenny K, Klein RS, Friedland GH: Heroin use during methadone maintenance treatment: the importance of methadone dose and cocaine use. Am J Public Health, 1995, 85, 83-88.

13. Hooks MS, Duffy P, Striplin C, Kalivas PW: Behavioral and neurochemical sensitization following cocaine selfadministration. Psychopharmacology (Berl), 1994, 115, 265-272.

14. Introini-Collison IB, McGaugh JL: Cocaine enhances memory storage in mice. Psychopharmacology (Berl), 1989, 99, 537-541.

15. Kreek MJ: Methadone-related opioid agonist pharmacotherapy for heroin addiction. History, recent molecular and neurochemical research and future in mainstream medicine. Ann NY Acad Sci, 2000, 909, 186-216.

16. Krueger DD, Howell JL, Oo H, Olausson P, Taylor JR, Nairn AC: Prior chronic cocaine exposure in mice induces persistent alterations in cognitive function. Behav Pharmacol, 2009, 20, 695-704.

17. Leri F, Bruneau J, Stewart J: Understanding polydrug use: review of heroin and cocaine co-use. Addiction, 2003, 98, 7-22.

18. Leri F, Sorge RE, Cummins E, Woehrling D, Pfaus JG, Stewart J: High-dose methadone maintenance in rats: effects on cocaine self-administration and behavioral side effects. Neuropsychopharmacology, 2007, 32, 2290-2300.

19. Magura S, Nwakeze PC, Demsky SY: Pre- and intreatment predictors of retention in methadone treatment using survival analysis. Addiction, 1998, 93, 51-60.

20. Manzanedo C, Aguilar MA, Rodriguez-Arias M, Minarro J: Effects of dopamine antagonists with different receptor blockade profiles on morphine-induced place preference in male mice. Behav Brain Res, 2001, 121, 189-197.

21. Marsden J, Eastwood B, Bradbury C, Dale-Perera A, Farrell M, Hammond P, Knight J, Randhawa K, Wright $\mathrm{C}$ : Effectiveness of community treatments for heroin and crack cocaine addiction in England: a prospective, intreatment cohort study. Lancet, 2009, 374, 1262-1270.

22. Mattick RP, Breen C, Kimber J, Davoli M: Methadone maintenance therapy versus no opioid replacement therapy for opioid dependence. Cochrane Database Syst Rev, 2009, CD002209.

23. McCance-Katz EF, Jatlow P, Rainey PM: Effect of cocaine use on methadone pharmacokinetics in humans. Am J Addict, 2010, 19, 47-52.

24. Mucha RF, Iversen SD: Reinforcing properties of morphine and naloxone revealed by conditioned place preferences: a procedural examination. Psychopharmacology (Berl), 1984, 82, 241-247.

25. Peles E, Schreiber S, Adelson M: Factors predicting retention in treatment: 10-year experience of a methadone maintenance treatment (MMT) clinic in Israel. Drug Alcohol Depend, 2006, 82, 211-217.

26. Pierce TL, Hope W, Raper C: The induction and quantitation of methadone dependence in the rat. J Pharmacol Toxicol Methods, 1996, 36, 137-146.

27. Popik P, Danysz W: Inhibition of reinforcing effects of morphine and motivational aspects of naloxoneprecipitated opioid withdrawal by NMDA receptor antagonist, memantine. J Pharmacol Exp Ther, 1997, 280, 854-865.

28. Popik P, Kozela E, Wróbel M, Wozniak KM, Slusher BS: Morphine tolerance and reward but not expression of morphine dependence are inhibited by the selective glutamate carboxypeptidase II (GCP II, NAALADase) inhibitor, 2-PMPA. Neuropsychopharmacology, 2003, 28, 457-467.

29. Robinson TE, Berridge KC: Incentive-sensitization and addiction. Addiction, 2001, 96, 103-114.

30. Shippenberg TS, LeFevour A, Thompson AC: Sensitization to the conditioned rewarding effects of morphine and cocaine: differential effects of the $\kappa$-opioid receptor agonist U69593. Eur J Pharmacol, 1998, 345, 27-34.

31. Spyraki C, Fibiger HC, Phillips AG: Attenuation of heroin reward in rats by disruption of the mesolimbic dopamine system. Psychopharmacology (Berl), 1983, 79, 278-283.

32. Steinpreis RE, Rutell AL, Parrett FA: Methadone produces conditioned place preference in the rat. Pharmacol Biochem Behav, 1996, 54, 339-341.

33. Taracha E, Chrapusta SJ, Lehner M, Skórzewska A, Maciejak P, Szyndler J, Plaznik A: Morphine and methadone pre-exposures differently modify brain regional Fos protein expression and locomotor activity responses to morphine challenge in the rat. Drug Alcohol Depend, 2008, 97, 21-32.

34. Taracha E, Chrapusta SJ, Lehner M, Skórzewska A, Płaźnik A: Methadone is substantially less effective than morphine in modifying locomotor and brain Fos responses to subsequent methadone challenge in rats. Prog Neuropsychopharmacol Biol Psychiatry, 2009, 33, 1032-1039.

35. Tzschentke TM: Measuring reward with the conditioned place preference (CPP) paradigm: update of the last decade. Addict Biol, 2007, 12, 227-462.

36. Vanderschuren LJ, Kalivas PW: Alterations in dopaminergic and glutamatergic transmission in the induction and expression of behavioral sensitization: a critical review of preclinical studies. Psychopharmacology (Berl), 2000, $151,99-120$.

37. Williamson A, Darke S, Ross J, Teesson M: The effect of persistence of cocaine use on 12-month outcomes for the treatment of heroin dependence. Drug Alcohol Depend, 2006, 81, 293-300.

Received: February 12, 2013; accepted: May 13, 2013. 